\title{
PREVALÊNCIA DE SOROVARES DE Salmonella ISOLADOS DE AVES NO BRASIL ${ }^{1}$
}

\author{
Ernesto Hofer $^{2}$, Sebastião Januário da Silva Filho ${ }^{2,3}$ e Eliane \\ Moura Falavina dos Reis ${ }^{2}$
}

\begin{abstract}
Hofer E., Silva Filho S.J. \& Reis E.M.F. 1997. [Prevalence of Salmonella serovars isolated from birds in Brazil.] Prevalência de sorovares de Salmonella isolados de aves no Brasil. Pesquisa Veterinária Brasileira 17(2):55-62. Depto Bacteriologia, Instituto Oswaldo Cruz/ FIOCRUZ, Rio de Janeiro, RJ 21045-900, Brazil.

Salmonella strains were isolated from ill and shedding birds in several regions of Brazil between 1962 and 1991. Serotyping of 2123 isolates showed 90 serovars pertaining to 14 serogroups. There was a predominance of groups 0:9 (40.0\%), 0:4 (33.3\%), 0:7 (10.6\%) and O:3,10 (6.7\%). Major serovar diversity was found to serogroup 0:7 that accounted for 22 different types, followed by serogroups $0: 4,0: 3,10$ and $0: 9$ with 19,15 and 10 serotypes respectively. An average of 10.8 serovars was isolated per year. $S$. Gallinarum, $S$. Pullorum, $S$. Typhimurium, $S$. Heidelberg, $S$. Enteritidis and $S$. Infantis were the most frequent serovars found over the 30 years, representing $65 \%$ to $67 \%$ of the total of isolates. Bacteriological and epidemiological aspects concerning a number of serotypes are discussed.
\end{abstract}

INDEX TERMS: Birds, Salmonella, prevalence, serogroups, serovars.

SINOPSE.- Foram caracterizadas antigenicamente amostras de Salmonella isoladas de aves (portadoras e doentes) provenientes de diversas regiões do país durante o período de 1962 a 1991. Nas 2123 culturas analisadas foram reconhecidos 90 sorovares, distribuídos em 14 sorogrupos com predominância dos grupos 0:9 (40,0\%), 0:4 (33,3\%), 0:7 (10,6\%) e 0: 3,10 $(6,7 \%)$. A maior diversidade de sorovares foi reconhecida no sorogrupo 0:7 com 22 tipos distintos, secundado por 0:4, O:3,10 e 0:9, constituídos de 19, 15 e 10 sorotipos, respectivamente. No computo geral, foi determinada a média de 10,8 sorovares isolados por ano. Os sorovares classificados como muito frequentes nos três decênios, representando 65 a 67\%, dos isolamentos, foram $S$. Gallinarum, S. Pullorum, $S$. Typhimurium, $S$. Heidelberg, $S$. Enteritidis e $S$. Infantis. Considerações de natureza bacteriológica e epidemiológica foram discutidas em relação a alguns dos sorotipos prevalentes.

TERMOS DE INDEXAÇÃO: Aves, Salmonella, prevalência, sorogrupos, sorovares.

\footnotetext{
${ }^{1}$ Aceito para publicação em 22 de abril de 1997.

2 Depto Bacteriologia, Instituto Oswaldo Cruz/FIOCRUZ, Av. Brasil 4365, Manguinhos, Rio de Janeiro, RJ 21045-900.

${ }^{3}$ In memoriam, falecido em 10.1.89.
}

\section{INTRODUÇÃO}

A análise epidemiológica das doenças infecciosas está sedimentada em alguns paramêtros constituintes da história natural dessas ocorrências. Assim, um dos aspectos fundamentais do problema, reside no isolamento e identificação conclusiva do agente etiológico. Particularizando às salmoneloses aviárias, esta condição propicia em primeiro plano o conhecimento da incidência e/ou prevalência dos sorovares de Salmonella, possibilitando, posteriormente, estabelecer confrontos de suas frequiências em diversas regiões, bem como o rastreamento dos sorotipos predominantes, visando a implantação de medidas preventivas ou de controle (Edwards 1958, Hofer 1985, Snoeyenbos \& Williams 1991).

Apesar de toda ênfase dada na atualidade ao problema das salmoneloses no mundo (Tauxe 1991), ainda assim, em nosso meio são muito exíguas as informações que detalharam a ocorrência de sorovares de Salmonella em aves em diferentes situações clínica e epidemiológica (Reis \& Nóbrega 1956, Bueno et al. 1971, Giorgi 1972, Ávila et al. 1974, Silva 1978, Hofer 1985).

No presente trabalho, analisa-se a distribuição de sorotipos de Salmonella isolados de diversas espécies de aves e oriundas de algumas áreas avícolas do país, compreendendo um estudo contínuo de 30 anos. 


\section{MATERIAL E MÉTODOS}

Durante o período de 1962 a 1991, o Laboratório de Enterobactérias do Departamento de Bacteriologia do Instituto Oswaldo Cruz/ FIOCRUZ, recebeu 2210 amostras suspeitas de Salmonella e das quais,, $2123(96,06 \%)$ foram confirmadas como pertencentes ao gênero. Deste total reconhecido, $1756(82,71 \%)$ tiveram como fonte de infecção Gallus gallus, com predominância de animais jovens. Em plano bem inferior, situaram-se os isolamentos de perus (165 - 7,7\%), patos $(143-6,7 \%)$, marrecos $(21-0,98 \%)$, codornas ( $18-0,84 \%)$, pombos (10 - 0,47\%), aves e pássaros silvestres $(10-0,47 \%)$.

Quanto a origem das amostras recebidas, destaca-se o estado de Santa Catarina, que praticamente contribuiu com a metade da amostragem, como está assinalado no Quadro 1.

Quadro 1. Distribuição por área geográfica das salmonelas isoladas no período de 1962 a 1991

\begin{tabular}{lcr}
\hline \multicolumn{1}{c}{ Origem } & Número & $\%$ \\
\hline Ceará & 9 & 0,42 \\
Pernambuco & 22 & 1,03 \\
Bahia & 118 & 5,55 \\
Goiás & 13 & 0,61 \\
Distrito Federal & 6 & 0,28 \\
Minas Gerais & 584 & 27,50 \\
Espírito Santo & 4 & 0,18 \\
Rio de Janeiro & 64 & 3,01 \\
São Paulo & 176 & 8,29 \\
Paraná & 93 & 4,38 \\
Santa Catarina & 1032 & 0,09 \\
Rio Grande do Sul & 2 & \\
& & 99,95
\end{tabular}

As cepas foram encaminhadas na maioria das vezes por entidades privadas e mais discretamente por instituições públicas federais e estaduais, quase sempre mantidas e remetidas em agar nutriente ou em outros meios básicos, sendo algumas vezes acompanhadas de um breve relato clínico-epidemiológico, principalmente, quando do acontecimento de surtos.

As fontes de isolamento quando referidas, foram sangue de coração, vísceras quase sempre em "pools" (coração, fígado e pulmão) e fezes. Em menor escala, material encefálico, saco de gema, ovário, oviduto, vesícula biliar e medula de ossos longos.

As culturas recebidas, foram analisadas quanto a sua pureza, através do reisolamento em meio seletivo-indicador (Agar EMB-Difco) e em seguida, recolhendo-se três colônias em fase lisa, para a caracterização do perfil bioquímico compatível do gênero (Costa \& Hofer 1972) e mais especificamente, detendo-se na diferenciação dos sorovares Pullorum e Gallinarum. Neste caso utilizou-se uma adaptação do esquema de Trabulsi \& Edwards, 1962, verificando-se a ação fermentativa sobre a glicose (com ou sem produção de gás) e dulcitol; produção de $\mathrm{H}_{2} \mathrm{~S}$ e mobilidade em meio de SIM; pesquisa da ornitina descarboxilase e utilização do tartarato no meio de Jordan.

A caracterização antigênica foi realizada após a comprovação bioquímica do gênero sendo concretizada, pela determinação das estruturas somáticas e flagelares, através do processo de soroaglutinação rápida (Costa \& Hofer 1972). Nesta etapa foram utilizados antissoros polivalentes e monovalentes somáticos e flagelares produzidos pelo Laboratório de Enterobactérias, Instituto Oswaldo Cruz/FIOCRUZ. A representação dos sorovares obedeceu a orientaçào de Le Minor \& Popoff 1987.
Em relação ao nível de frequência dos sorovares foi elaborado um critério de classificação quantitativa, seguindo em linhas gerais àquele apresentado por Hofer \& Ernandez (1990) para Vibrio cholerae não $\mathrm{O}_{1}$. Assim, foram distribuidos sob a sigla de sorovares "muito frequentes", aqueles cuja soma dos percentuais totaliza entre 65 a $67 \%$, com uma variação permissível de $\pm 2 \%$. Os escalões subsequentes foram designados como "frequentes", para aqueles cuja percentagem somada ao dos sorotipos "muito frequentes"atinge entre 85 a $87 \%$ com $\pm 1 \%$ de variação; sorovares "comuns mas não frequentes", que somados as duas taxas anteriores, obtem-se 95 a $96 \%$ com $\pm 0,5 \%$ e, finalmente, os denominados "acidentais ou raros"que adicionados aos precedentes, perfazem $100 \%$.

\section{RESULTADOS}

Das 2123 amostras de Salmonella analisadas foram reconhecidos 90 sorovares, incluindo as variantes sorológicas e a forma rugosa, cuja distribuição segundo os sorogrupos pertencentes estão assinalados no Quadro 2.

A maior diversidade de sorovares, paradoxalmente, não está localizada nos sorogrupos numericamente mais frequentes, 0:9 e 0:4, mas em 0:7, representados por 22 tipos reconhecidos nas 226 amostras deste grupo. Em plano secundário, destacam-se 0:4, 0:3,10 e 0:9, com 19, 15 e 10 sorovares, respectivamente. (Quadro 2)

Em relação ao número de sorovares identificados anualmente, assinala-se que as médias obtidas nas três fases, isto é, 1962-1971; 1972-1981 e 1982-1991, foram 6,2, 6,5 e 19,8, respectivamente, tendo como média geral 10,8 sorovares/ano reconhecidos, segundo os dados da Figura 1. Ainda focalizando as ocorrências dos sorovares nos três decênios (Quadros 2 e 5), mas tomando-se por base as frequências de isolamentos por anos, verifica-se na Figura 2, que os sorovares Gallinarum e Pullorum, sempre foram detectados. Por outro lado, excetuando-se S.Typhimurium, todos os demais sorovares se situaram numa faixa de frequência entre 5 a 13 anos de incidência (Fig. 2). Aliás, infere-se deste dado um aspecto muito interessante, representado pela ausência de uma relação entre o número de amostras isoladas de um determinado sorotipo (Quadros 2 e 5) com a sua frequência anual, nos três decênios (Fig. 2 ). Este acontecimento é bem evidente com os sorovares Heidelberg e Enteritidis.

Quanto a classificação adotada de acordo com o nível de ocorrência dos sorovares nos diferentes períodos, os resultados estão consignados nos Quadros, 3, 4 e 5, associando-se nesta última a origem geográfica dos isolados.

Finalmente na Figura 3, projeta-se as ocorrências anuais dos dois únicos sorovares, Gallinarum e Pullorum, que foram detectados em todo o período de análise e que, graficamente, retratam as características enzoóticas das duas etiologias, acompanhadas de picos sugestivos de surtos epizoóticos em algumas fases.

\section{DISCUSSÃO}

A salmonelose é uma das zoonoses mais problemáticas para a saúde pública em todo o mundo, em razão da elevada endemicidade, alta morbidade e acima de tudo, pela dificuldade no controle. Este desafio resulta do extraordinário número de fontes de infecção, envolvendo praticamente todo o 
Quadro 2. Distribuição numérica e percentual dos sorovares e variantes de Salmonella identificados e classificados de acordo com os seus sorogrupos

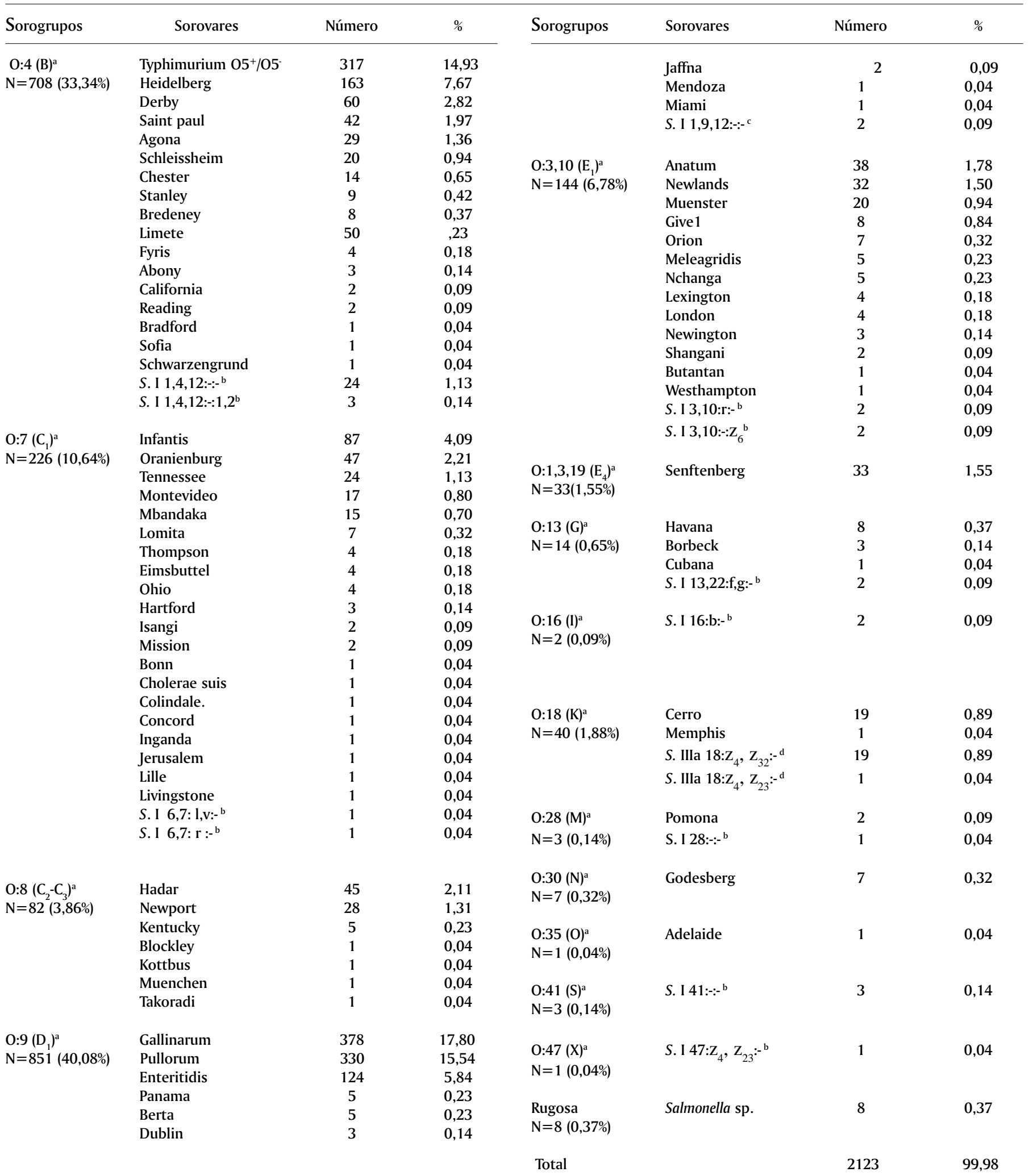

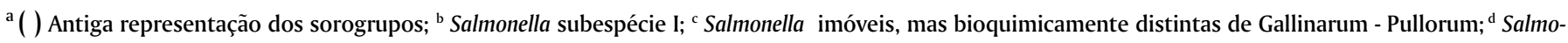
nella subespécie IIIa (antigo gênero Arizona, monofásica). 


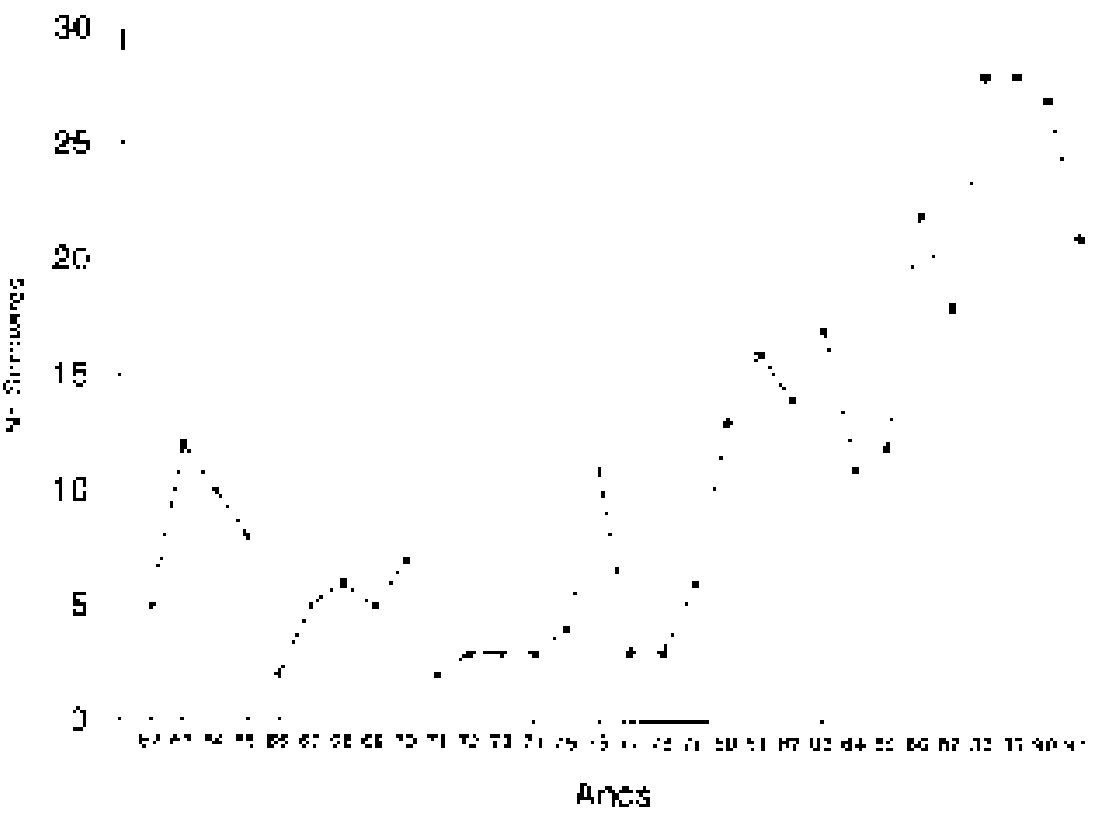

Fig. 1. Número de Salmonella anualmente identificados no período de 1962 a 1991.

escalão filogenético dos vertebrados, alguns dos quais, fonte de proteína animal para o homem (Hofer \& Reis 1994).

As aves situam-se neste contexto, como um dos mais destacados veículos de infecção das salmonelas, circunstanciado pela característica de propagá-las a outras espécies animais, inclusive ao homem, com relativa facilidade (Morse \& Duncan 1974). Em grande parte este acontecimento decorre, na maioria dos países, pelo extraordinário crescimento da indústria avícola, dentro de uma visão econômica tipicamente de produção.

É oportuno também enfatizar que, as infecções por salmonelas nas aves apresentam um notavél espectro clínico, tendo numa das faces, os quadros graves que implicam na maioria das vezes na eliminação dos lotes infectados como na pulorose e no tifo aviário. Entretanto, o grande enigma desta zoonose reside na outra face, cuja forma clínica quase

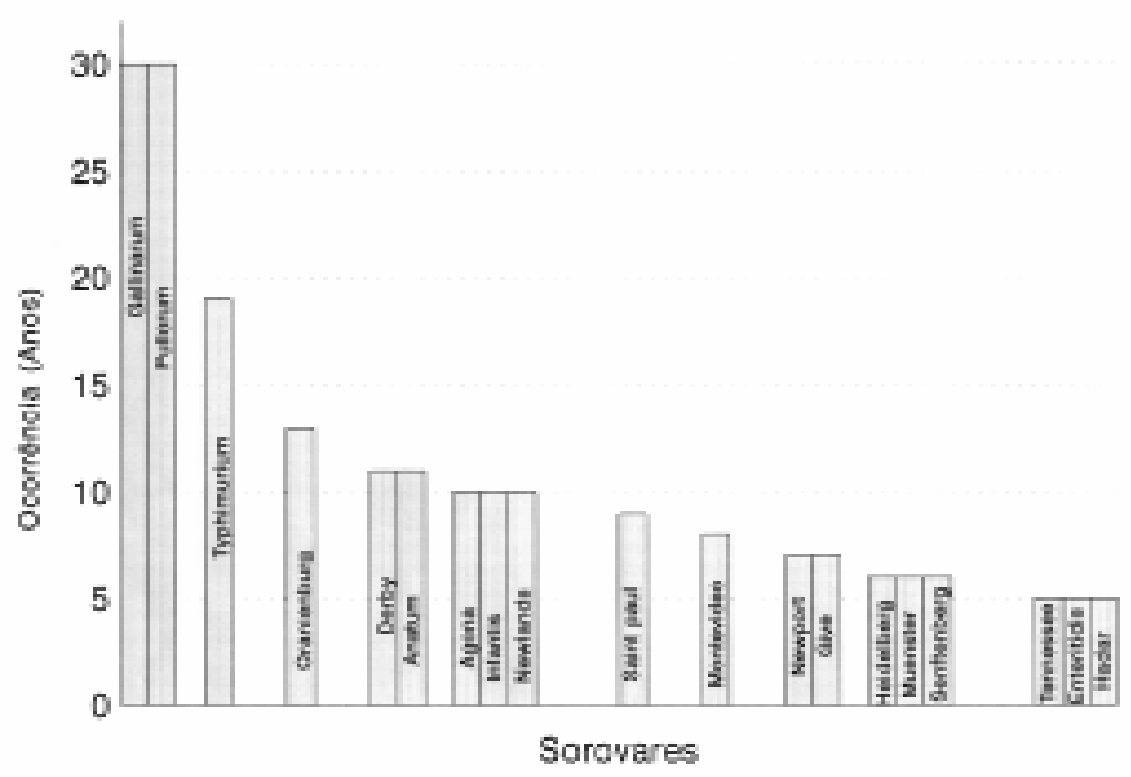

Fig. 2. Detecção em anos de alguns sorovares de Salmonella no período tricenal de 1962-11991. 
Quadro 3. Distribuição dos 2115 sorovares de Salmonella classificados segundo o nível de ocorrência no período de 1962 a 1991

Sorovares de Salmonella

Muito frequentes Frequentes Comuns mas não frequentes Acidentais ou raros

$(65$ a $67 \% \pm 2 \%)(85$ a $87 \% \pm 1 \%) \quad(95$ a $96 \% \pm 0,5 \%) \quad$ (até $100 \%)$

\begin{tabular}{|c|c|c|c|c|}
\hline Gallinarum & Derby & Cerro & Abony & Cholera suis \\
\hline Pullorum & Oranienburg & $S_{\underline{\text { III }}}$ 18: $\mathrm{Z}_{4}, \mathrm{Z}_{32}:-$ & S. I 1,4,12:-: 1,2 & Colindale \\
\hline Typhimurium & Hadar & Give $^{a}$ & Hartford & Concord \\
\hline Heidelberg & Saint paul & Montevideo & Dublin & Inganda \\
\hline Enteritidis & Anatum & Mbandaka & Newington & Jerusalem \\
\hline \multirow[t]{19}{*}{ Infantis } & Senftenberg & Chester & Borbeck & Lille \\
\hline & Newlands & Stanley & S. I $41:-:-$ & Livingstone \\
\hline & Agona & Bredeney & California & S. I 6,7:1,v:- \\
\hline & Newport & Havana & Reading & S. I 6,7:r:- \\
\hline & S. I 1,4,12:-:- & Lomita & Isangi & Blockley \\
\hline & Tennessee & Godesberg & Mission & Kottbus \\
\hline & Schleissheim & Orion & Jaffna & Muenchen \\
\hline & Muenster & Limete & S. I 1,9,12:-:- & Takoradi \\
\hline & & Kentucky & Shangani & Mendoza \\
\hline & & Panama & S. I 3,10:r:- & Miami \\
\hline & & Berta & S. I 3,10:-:z & Butantan \\
\hline & & Meleagridis & S. I 13,22:f,g:- & Westhampton \\
\hline & & Nchanga & S. I 16:b:- & Cubana \\
\hline & & Fyris & Pomona & Memphis \\
\hline & & Thompson & Bradford & S. III 18: $\mathrm{Z}_{4}, \mathrm{Z}_{23}$ :- \\
\hline & & Eimsbuettel & Sofia & S. I 28:-:- \\
\hline & & Ohio & Schwarzengrund & Adelaide \\
\hline & & Lexington & Bonn & S. I 47: $\mathrm{Z}_{4}, \mathrm{z}_{23}:-$ \\
\hline & & London & & \\
\hline$N=1399(66,12 \%)$ & $\mathrm{N}=442(86,95 \%)$ & $\mathrm{N}=202(96,35 \%)$ & $\mathrm{N}=$ & $9 \%)$ \\
\hline
\end{tabular}

Quadro 4. Classificação dos sorovares de Salmonella de acordo com as três fases compreendidas entre 1962 e 1991

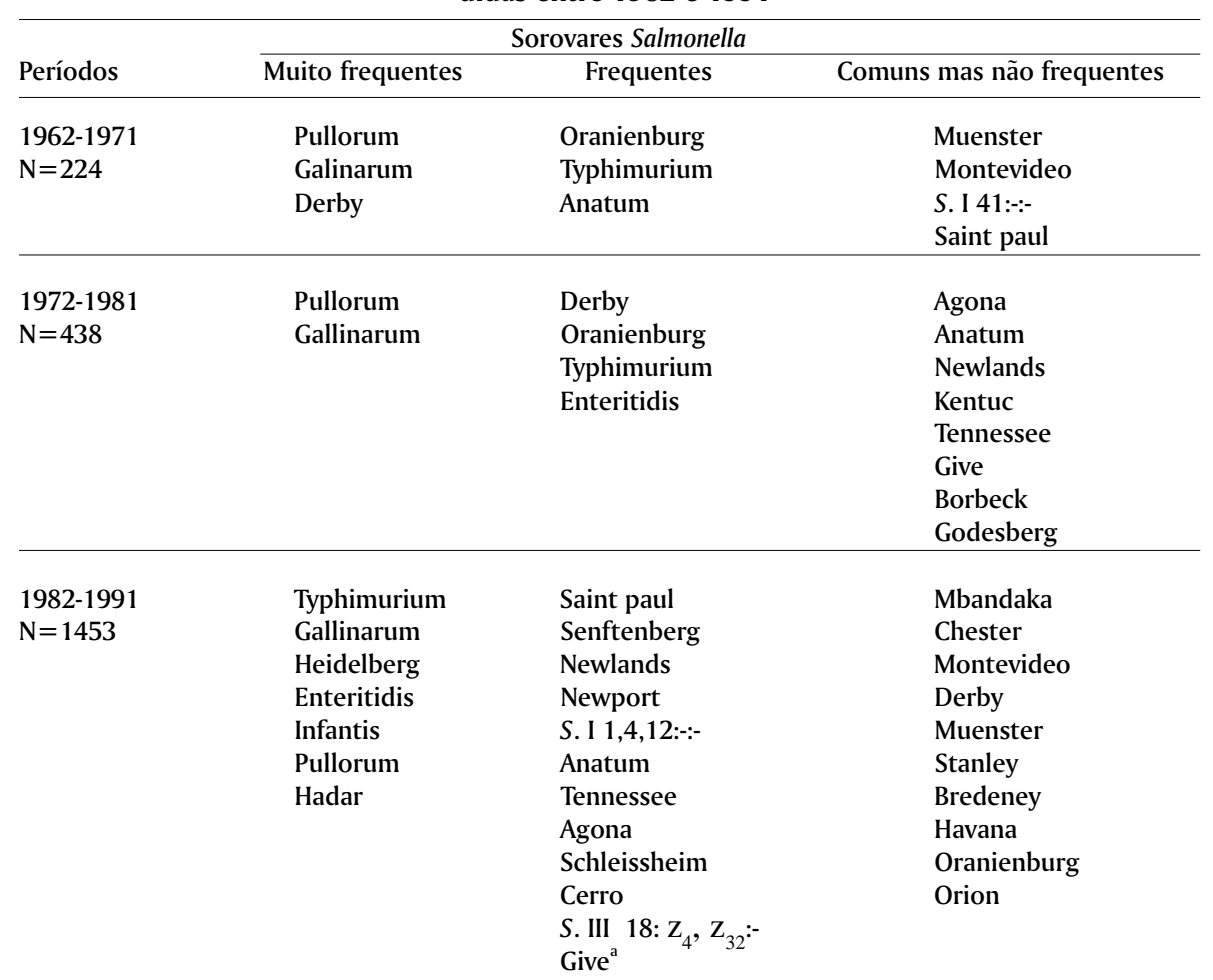




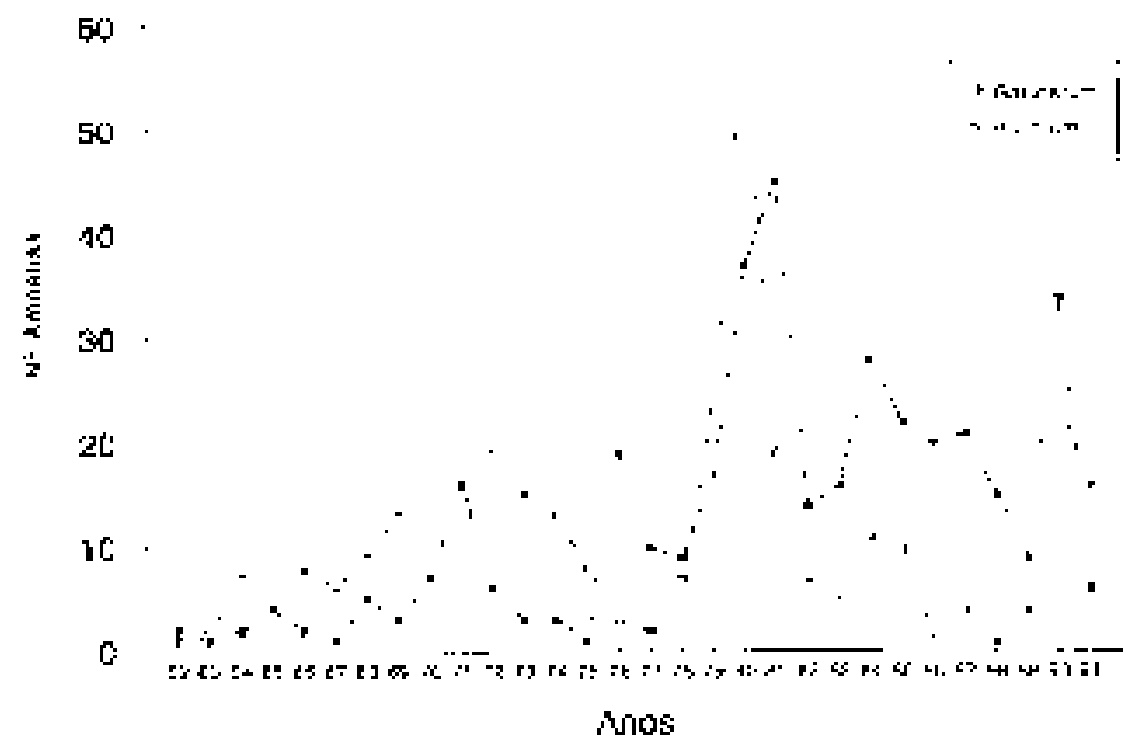

Fig. 3. Distribuição de Salmonella Pullorum e S. Gallinarum no período de 1962 a 1991.

sempre é inaparente e rotulada em patologia aviária, como infecções paratíficas. Estas também são responsáveis por uma queda da produtividade do plantel quando aparentes, além de sorrateiramente se propagar para outras espécies animais veiculadas pelas fezes das aves infectadas ou por seus produtos contaminados.

O grau de suscetibilidade das aves as salmonelas é um fato evidente, considerando as inúmeras investigações realizadas em diferentes partes do mundo, Edwards (1958), Aserkoff et al. (1970) e Bruner (1973) nos E.U.A., Brown et al. (1973) na Escócia, Sojka et al. (1975) na Inglaterra e Basu et al. (1975) na India. No Brasil, salientam-se as observações de Reis \& Nóbrega, (1956), Bueno et al. (1971), Costa et al. (1971), Giorgi (1972), Ávila et al. (1974), Silva (1978) e Hofer (1985).

Quadro 5. Distribuição numérica dos sorovares de Salmonella "muito frequentes" e "frequentes" no período de 1962 a 1991, segundo a origem geográfica

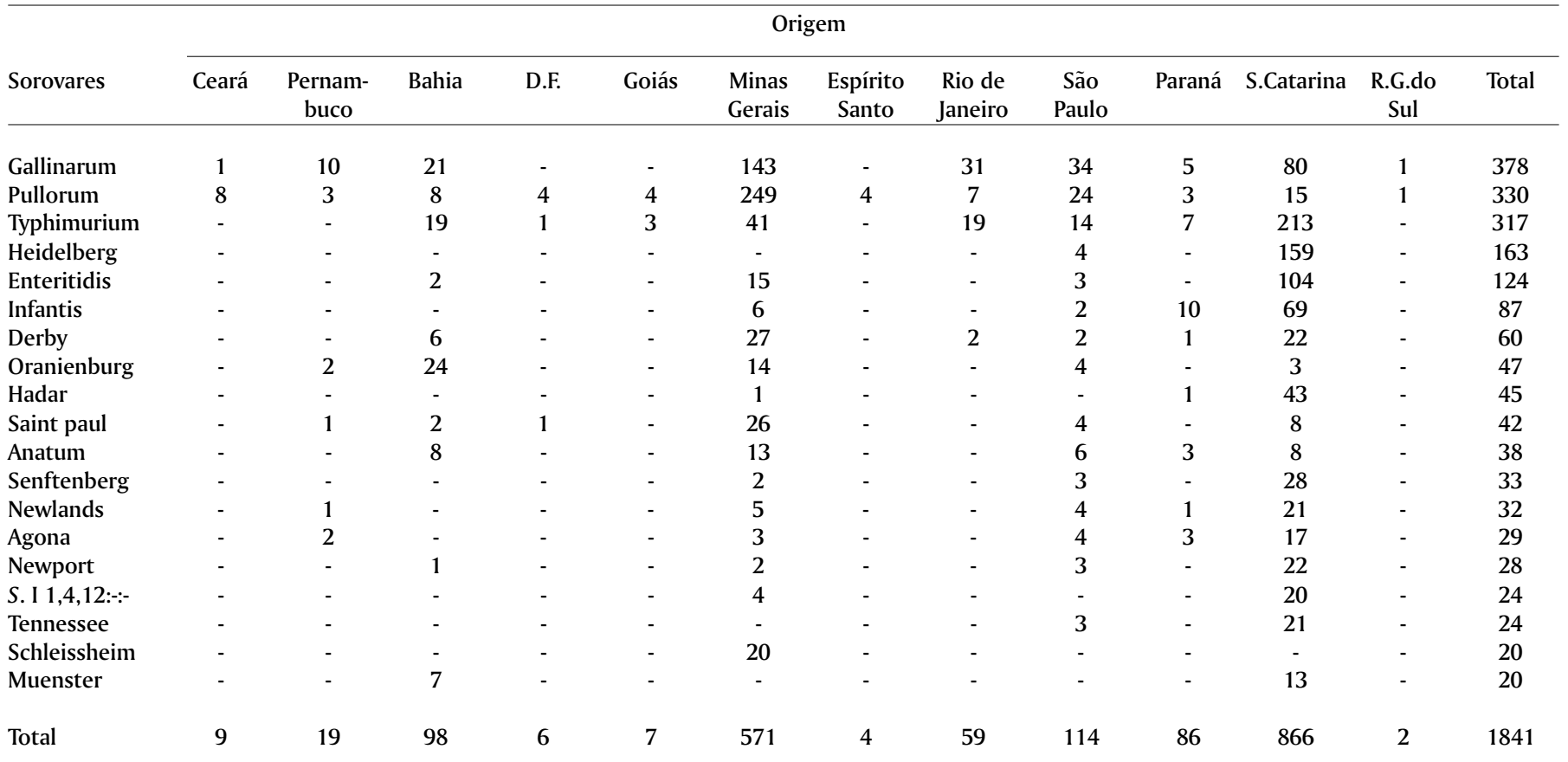


Na totalidade das referências consultadas, notifica-se uma gama relativamente numerosa de sorovares, não se excluindo os tipos clássicos como Gallinurum e Pullorum, que ocorrem mais proeminentemente nas áreas em que o controle ainda é incipiente ou não é efetuado. Os resultados consignados no Quadro 2, corroboram esta afirmação, tanto pela multiplicidade de sorovares identificadas como pela predominância dos agentes da pulorose e do tifo aviário.

Outro aspecto epidemiológico de suma importância reside nas flutuações dos sorovares dominantes numa região, quase sempre retratando primariamente este acontecimento nas aves com projeções futuras para outras fontes de infeç̧ões, como nos exemplos de $S$. Agona, $S$. Saint paul, $S$. Typhimurium, $S$. Hadar e na atualidade, $S$. Enteritidis. Sem dúvida, esta notória adaptação das salmonelas ao organismo dos galináceos, reafirma as observações de Edwards em 1958, que apontou que mais de $2 / 3$ dos isolados de animais, originavam-se das aves. Por sinal, esta projeção pode ser analisada na Figura 1, em que nos dois primeiros decênios mostrou uma média de sorovares constante, mas aumentando em três vezes no último período (1982-1991). Com muita probabilidade esta amplitude de sorovares tem como causa primordial a veiculação de salmonelas através das rações (Giorgi et al. 1971, Hofer 1985, Berchieri et al. 1989), aliado aos fatores estressantes que esses animais sofrem nas diversas fases de vida (Cooper 1994). Outro ponto capital, situa-se na tendência de concentrar os criadouros em determinadas regiões, por questões de logística e econômica, aumentando com isto a densidade populacional que favorece a transmissão das salmonelas, segundo Lahellec et al. (1986).

Por outro lado do ponto de vista estritamente bacteriológico, o conhecimento da prevalência de sorotipos de Salmonella numa determinada fonte de infecção ou região geográfica, propicia uma economia de tempo e de material empregados no diagnóstico das estruturas antigênicas por parte de laboratórios locais. Desta forma, tomando-se por base os aspectos assinalados nos Quadros 2, 3, 4 e 5 e Figura 2 , verifica-se que a utilização de um número limitado de antissoros somáticos e flagelares possibilitou a caracterização de aproximadamente $87 \%$ dos sorovares, classificados como "muito frequentes" e "frequentes". No caso de se considerar apenas a identificação dos grupos sorológicos (Quadro 2), salienta-se que em torno de $96 \%$ das salmonelas foram distribuídas entre os grupos 0:4 a 0:1, 3, 19, com acentuada predominância de 0:9, 0:4 e 0:7, constituindo $84 \%$ dos isolados.

Ainda na esfera laboratorial, ressalta-se a importância da utilização de certas provas bioquímicas rotineiras, mas especifícas no seu perfil para a identificação conclusiva dos sorovares Gallinarum e Pullorum, que permite ao laboratório um diagnóstico definitivo sem a necessidade de recorrer a caracterização antigênica somática.

É digno de menção a ocorrência proeminente de determinados sorovares nestes três decênios, associados quase sempre a introdução exógena da bactéria por uma fonte de infeç̧ão no estado portador, ou mesmo, doente. Exemplificam-se as situações decorrentes de infecções em pintos de um dia, importados dos EUA, como $S$. Oranienburg na Bahia; $S$. Infantis em Santa Catarina e $S$. Enteritidis em marrecos oriundos da Europa e distribuídos pelo estado do Rio de Janeiro. Em outros acontecimentos não foi possível rastrear a origem da salmonela, como na extraordinária propagação de $S$. Enteritidis e $S$. Typhimurium em patos criados no sul do país, o destaque de $S$. Heidelberg, $S$. Saint paul e $S$. Hadar em frangos, principalmente em Santa Catarina, além da associação de $S$. IIIa $18: z_{4}, z_{32}:-e S$. Chester em perus nesta mesma área.

Como ponto de referência para futuras análises epidemiológicas, salienta-se a incidência de $S$. Typhimurium $\mathrm{O}_{5}^{-}$em codornas e pombos e as infecções de $S$. Senftenberg nos galináceos, esta talvez como consequência de sua destacada ocorrência em matérias-primas e rações, na década de 80 (Hofer 1985).

Uma questão que merece ser abordada refere-se ao rastreamento de $S$. Enteritidis realizada pela fagotipagem, por Reis em 1994. Todas as isoladas de aves, enquadraram-se no lisotipo 4, enquanto as de origem humana da mesma área geográfica, se classificaram predominantemente como fagotipo 8. Este detalhe indicou que naquela ocasião, $S$. Enteritidis, reconhecida como principal agente de toxinfecção alimentar, provavelmente não tenha sido veiculada por aves e seus produtos, como em outras regiões do mundo (Rodrigue et al. 1990).

De forma similar, a lisotipia de algumas amostras de $S$. Typhimurium não possibilitaram reconhecer um elo de transmissão entre aves e outras fontes de infecção. A detecção dos lisotipos 193;99;19 e um contingente numeroso de amostras "não tipáveis" nas aves, não se coadunou com aqueles tipos fágicos reconhecidos nas espécies humana, bovina e suina, excetuando-se o lisotipo 193 (Hofer et al. 1979, Asensi et al. 1995).

Um aspecto interessante situa-se na prevalência dos sorovares mais comumente descritos nos inúmeros levantamentos realizados em diferentes partes do mundo e previamente mencionados. Considerando os resultados em pauta, o problema não fugiu a esta regra (Quadros 2, 3, 4 e 5), enfatizando-se que os sorovares classificados como "muito frequentes" e "frequentes", representando $87 \%$ dos isolados, estavam representados pelos sorotipos cosmopolitas. Claro que detectam-se oscilações de decênio para decênio (Quadro 4), resultantes das influências de fatores exógenos, particularmente, a veiculação através de rações contaminadas, associadas a introdução de aves portadoras no plantel, ou em menor escala por interferência do fenômeno de domiciliarização de outras espécies animais, isto é, cohabitantes nesse nicho ecológico.

Salienta-se ainda a ocorrência desta distribuição de maneira uniforme dos sorovares nas diversas áreas do país (Quadro 5), assim como, é possível verificar uma nítida distinção entre as regiões, quando se analisa as frequências de $S$. Gallinarum e $S$. Pullorum. Nos dados de Santa Catarina, os dois sorovares representam apenas $11 \%$ dos isolados, enquanto naqueles de Minas Gerais, Rio de Janeiro, São Paulo e Paraná, esta taxa varia de 50 a $69 \%$. Sem dúvida, este acontecimento retratou que nestas áreas, o controle tem sido precário, ou talvez, não implantado, o oposto de Santa Catarina, 
cujo maior problema reside nos sorovares responsáveis pelo paratifo e de grande ressonância em Saúde Pública, pelos processos de toxinfecção alimentar (Hofer \& Reis, 1994).

Vários autores, Osborne (1976), Silva (1978) e Snoeyenbos \& Williams (1991), são enfáticos em apontar que a instituição de medidas higiênicas em avicultura, implica na queda da prevalência da pulorose e do tifo aviário, entretanto, em nosso meio, a análise de três decênios consecutivos não corrobora com esta orientação. Os resultados contidos nos Quadros 2, 3, 4 e 5, indicam ainda a importância dos sorovares Gallinarum e Pullorum e a Figura 3, evidencia que nos dois primeiros períodos predominou o agente da pulorose, ocorrendo a inversão na última fase. Em síntese, a circulação dos dois sorovares nunca deixou de existir nos trinta anos de observação (Fig. 2), atingindo indiferentemente todas as regiões analisadas (Quadro 5), mostrando com isso uma situação enzoótica, tendo surtos epizoóticos frequentes, ou então, os picos retratados na Figura 3, resultaram da implementação de medidas sanitárias, monitoradas laboratorialmente. Aliás, Snoeyenbos \& Williams (1991) apontaram a América Latina, como uma das áreas no mundo em que os surtos de pulorose e tifo aviário aumentaram, drasticamente.

No computo geral, os resultados evidenciaram o desenvolvimento de um aspecto de extrema importância para os estudos da história natural das salmoneloses aviárias, isto é, a necessidade do isolamento e da caracterização dos sorovares de uma forma contínua. Isto determinou nas granjas e indústrias avícolas a implantação e implementação de laboratórios, que em diferentes níveis de atuação vem realizando o diagnóstico parcial ou completo de membros do gênero Salmonella.

Agradecimentos.- À toda equipe do antigo Laboratório de Enterobactérias do Instituto Oswaldo Cruz, pela execução de algumas etapas e, particularmente, às instituições públicas e privadas pela remessa das amostras bacterianas.

\section{REFERÊNCIAS}

Asensi M.D., Costa A.P., Reis E.M.F. \& Hofer E. 1995. Lysotypes and plasmidial profile of Salmonella serovar Typhimurium isolated from children with enteric processes in the cities of Rio de Janeiro, RJ and Salvador, BA - Brazil. Revta Inst. Med. Trop., São Paulo, 37:297-302.

Aserkoff B., Schroeder S.A. \& Brachman P.S. 1970. Salmonellosis in the United States - a five year review. Am. J. Epidemiol. 92:13-24.

Ávila F.A., Ferreira M.D. \& Silva E.N. 1974. Salmonella em carcaças de aves manipuladas nos abatedouros de Belo Horizonte. Arqs Esc. Vet. UFMG, Belo Horizonte, 26:211-214.

Basu S., Dewan M.L. \& Suri J.C. 1975. Salmonellosis in poultry in India during 1958-1973. Indian J. Med. Res. 63:1489-1494.

Berchieri Jr. A., Adachi S.Y., Calzada C.T., Paulillo A.C., Schoken-Iturrino R.P. \& Tavechio A.T. 1989. Farinha de carne como fonte de Salmonella em granja avícola. Pesq. Vet. Bras. 9:9-12.

Brown D.D., Duff R.H., Wilson J.E. \& Ross J.G. 1973. A survey of the incidence of infections with Salmonellae in broilers and broiler breeders in Scotland. Brit. Vet. J. 129:493-500.

Bruner D.W. 1973. Salmonella cultures typed during the years 1950-1971 for the service laboratories of the New York State Veterinary College at Cornell University. Cornell Vet. 63:138-143.

Bueno R.C., Baquer S.R. \& Nakano M. 1971. Doenças das aves em São Paulo. Revta Med. Vet., São Paulo, 6:225-266.
Cooper G.L. 1994. Salmonellosis - infections in man and the chicken: pathogenesis and the development of live vaccines - a review. Vet. Bull. 64:123-143.

Costa G.A., Hofer E., Costa M.D.M. \& Hage J.A. 1971. Tipos de Salmonellas ocorrentes em aves. III Congresso Brasileiro de Microbiologia, Belo Horizonte, MG. (Resumo)

Costa G.A. \& Hofer E. 1972. Isolamento e Identificação de Enterobactérias. Monografia, Inst. Oswaldo Cruz, Rio de Janeiro. 120 p.

Edwards P.R. 1958. Salmonellosis: Observations on incidence and control. Ann. N. York Acad. Sci. 70:598-613.

Giorgi W., Ohashi K. \& Araujo W.P. 1971. Farinha de carne e farinha de peixe como fontes de salmonelas para animais. Arqs Inst. Biol., São Paulo, 38: 59-62.

Giorgi W. 1972. Animais domésticos como portadores de salmonelas: significado epidemiológico e sua relação com a saúde pública. Tese de doutoramento, Instituto de Ciências Biológicas, USP, São Paulo. 55p.

Hofer E., Anderson E.S., Machado J.D.C., Dias J.C.A.R., Rodrigues D.P. \& Solari C.A. 1979. Considerações ecológicas e epidemiológicas sobre a subdivisão de Salmonella typhimurium em lisotipos e biotipos. X Congr. Bras. Microbiologia, Rio de Janeiro, RJ. (Resumo)

Hofer E. 1985. Epidemiologia das salmoneloses: Incidência de sorotipos de Salmonella em aves e rações (matérias-primas) no período de 1966-1984, p. 110-124. In: Anais do IV Simpósio do Centro Nacional de Pesquisa de Suínos e Aves - I Simpósio Catarinense de Sanidade Agrícola, Embrapa-CNPSA Doc. 9, Chapecó, Santa Catarina.

Hofer E. \& Ernandez D. 1990. Incidência de Vibrio cholerae não 01 em afluentes de estações de tratamento de esgotos da cidade do Rio de Janeiro, RJ. Revta Microbiol., São Paulo, 21:31-40.

Hofer E. \& Reis E.M.F. 1994. Salmonella serovars in food poisoning episodes recorded in Brazil from 1982 to 1991. Revta Inst. Med. Trop., São Paulo, 36:7-9.

Lahellec C., Colin P., Bennejean G., Paquin J., Guilherm A. \& Debois J.C. 1986. Influence of resident Salmonella on contamination of broiler flocks. Poultry Sci. 65:2034-2039.

LeMinor L. \& Popoff M.Y. 1987. Designation of Salmonella enterica sp. nov. as the type and only species of the genus Salmonella. Int. J. Syst. Bacteriol. 37:465-468.

Morse E.V. \& Duncan M.A. 1974. Salmonellosis an environmental health problem. J. Am. Vet. Med. Assoc. 165:1015-1019.

Osborne A.D. 1976. Salmonella infection in animal and birds. Royal Soc. Hlth J. 96:30-33.

Reis J. \& Nóbrega P. 1956. Salmoneloses. Tratado de Doenças das Aves. $2^{\text {a }}$ ed. Edições Melhoramentos, São Paulo, p. 53-89.

Reis E.M.F. 1994. Análise de marcadores epidemiológicos de Salmonella enteritidis oriundos de diferentes fontes de infecção e de regiões do país. Tese Mestrado, Curso de Pós-Graduação em Microbiologia Veterinária, UFRRJ. 69 p.

Rodrigue D.C., Tauxe R.V. \& Rowe B. 1990. International increase in Salmonella enteritidis: A new pandemic? Epidemiol. Infect. 105:21-27.

Silva E.N. 1978. Salmonelas em galinhas e perus reprodutores de criação industrial. Estudo microbiológico com especial referência a Salmonella arizonae e avaliação da transmissão pelo ovo. Tese de Doutorado, Instituto de Ciências Biomédicas, USP, São Paulo. 90 p.

Snoeyenbos G.H. \& Williams J.E. 1991. Salmonellosis, p. 73-86. In: B.W. Calnek, H.J. Barnes, C.W. Beard, W.M. Reid \& H.W. Yoder (ed.) Diseases of Poultry. 9th ed. lowa State University Press, Ames.

Sojka W.J., Wray C., Hudson E.B. \& Benson J.A. 1975. Incidence of Salmonella infection in animals in England and Wales, 1968-1973. Vet. Rec. 96:280284.

Tauxe R.V. 1991. Salmonella: A postmodern pathogen. J. Food Protect. 54:563568.

Trabulsi L.R. \& Edwards P.R. 1962. The differentiation of Salmonella pullorum and Salmonella gallinarum by biochemical methods. Cornell Vet. 52: 563569. 